\title{
To 80th Birthday Anniversary of Professor Dmitrii Nikolaevich Suglobov
}

DOI: $10.1134 / \mathrm{S} 1066362211010152$

On December 28, 2010, Honored Scientist of the Russian Federation, Winner of the USSR State Prize and Khlopin Prize of the Russian Academy of Sciences, Doctor of Chemical Sciences, Professor Dmitrii Nikolaevich Suglobov was 80.

More than half-century period of the scientific activity of Dmitrii Nikolaevich is associated with the Khlopin Radium Institute, to which he came in 1958 as a postgraduate student after graduation from the Leningrad State University (LGU) and several years of work at the Chair of Inorganic Chemistry of LGU. At the Radium Institute, Suglobov defended the candidate's (1961) and doctoral (1970) dissertations and passed the way from a postgraduate student and junior researcher to the head of a laboratory and a sector. Today he works at the Radium Institute as a principal researcher.

At the Radium Institute, Suglobov's name is mainly associated with the basic research in the field of the chemistry of radioactive elements. The scope of Suglobov's scientific interests is extremely wide. It includes the coordination chemistry of actinides (primarily of uranium, neptunium, plutonium, and americium in penta- and hexavalent states), organometallic chemistry, electronic and vibrational spectroscopy, photochemistry, chemistry of rare-earth elements, chemistry of nonaqueous solutions and extraction processes, chemistry of technetium carbonyl compounds, volatile compounds of radioelements, as well as environmental problems (migration of radioactive isotopes in soils), nuclear power engineering (problems of alternative fuel cycles), and many other problems. In the research team headed by Dmitrii Nikolaevich for more than three decades, a special, "Suglobov's" style of research work has been built up, when every researcher aimed to gain insight into the essence of phenomena being studied, to understand their causes, when the in-depth research was never sacrificed for obtaining a quick result. Suglobov's papers are characterized by systematic approach, detailed analysis of the data obtained, and ability to derive maximum information from the experimental results.

Dmitrii Nikolaevich was never afraid of initiating studies in fields new for him and of mastering new research methods. And in all the fields of Suglobov's research activities, he acquired authority both in Russia and in other countries.

The scientific authority and exactingness of Dmitrii Nikolaevich are combined with personal modesty, with benevolence and respect to colleagues. He does not consider shameful to ask collaborators' advice on scientific problems and is always attentive to their opinion. His authority is the authority of knowledge, ideas, and arguments, rather than the authority of post and regalia.

For more than 25 years, Dmitrii Nikolaevich is Deputy Editor-in-Chief of Raidokhimiya/Radiochemistry journal and one of the most active authors and referees of the journal. He made an incalculable contribution to ensuring regular issue of the journal in the perturbation period difficult for the Russian science. He always takes care of maintaining high scientific level of the journal.

At the age of 80, D.N. Suglobov is still full of new scientific ideas and actively looks for possiblities and ways of implementing them. The Editorial Board and Editorial Staff of Radiokhimiya/Radiochemistry journal congratulate Dmitrii Nikolaevich on his jubilee and wish him sound health, longevity, and new achievements for the welfare of Russian science. 